\title{
THE REDOX STATUS OF MALARIA-INFECTED ERYTHROCYTES : AN OVERVIEW WITH AN EMPHASIS ON UNRESOLVED PROBLEMS
}

\author{
GINSBURG H. AND ATAMNA H.*
}

\section{Summary :}

The various mechanisms involved in the redox defence of normal erythrocytes are adequately known. They are herein brieflly reviewed, outlining the principal enzymes and metabolic pathways, such as superoxide dismutase, catalase, glutathione peroxidase and reductase, the hexose monophosphate shunt (HMS) and glutathione synthesis and turnover. The intraerythrocytic malaria parasite is imposing an oxidative stress on its host cell. Malaria-infected cells produce $\mathrm{O}_{2}^{-}, \mathrm{H}_{2} \mathrm{O}_{2}$, enhance lipide peroxidation and activate host cell HMS. This stress is produced during the digestion of host cell hemoglobin by the parasite. Hence, both parasite and host cell must be able to confront this stress. The antioxidant defence systems of the parasite and the response of those systems in the infected host cell are reviewed, underscoring unresolved problems. Nothing is virtually known on the parasite's glutathione metabolism, and on possible interactions between host cell and parasite antioxidant defence systems. The postulate that 1. host cell activated HMS in conjunction with purine salvage can provide purine nucleotides to the parasite, and 2. that glutathione transferase can participate in parasite resistance to antimalarial drugs, are also discussed.

KEY WORDS : erythrocyte. malaria. Plasmodium falciparum. redox metabolism. glutathione. hexose-monophosphate shunt. oxidative radicals. purine nucleotides.

MOTS CLES : érythrocyte. malaria. Plasmodium falciparum. métabolisme redox. glutathion. shunt hexose-monophosphate. radicaux oxydants. nucléotides puriques.

\section{INTRODUCTION}

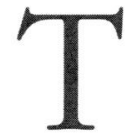
he redox status of malaria infected erythrocytes has been the subject of intense investigations and reviews in past years (Vennerstrom \& Eaton, 1988 ; Golenser \& Chevion, 1989 ; Hunt \& Stocker, 1990). It is generally accepted that the intraerythrocytic malaria parasite exerts an oxidative stress on its host erythrocyte ; that externally applied oxidative stress is antagonistic to survival and propagation of the malaria parasite, and that pro-oxidant agents are effective inhibitors of parasite growth in vitro and in vivo. The host's response to malaria involves, among others, oxidative attack on intraerythrocytic parasites by activated macrophages. This perception is based mostly on phenomenological observations, but relatively little is known on the redox metabolism of the parasite itself, or how the latter may affect that of the host cell. In this essay we shall briefly review our present knowledge and underscore those problems

* Department of Biological Chemistry, Institute of Life Sciences, Hebrew University, Jerusalem 91904, Israel.
Résumé : LES SYSTEMES REDOX DANS L'HÉMATIE INFECTÉE PAR LES PARASITES DU PALUDISME : UNE REVUE METTANT L'ACCENT SUR LES PROBLEMES NON RÉSOLUS.

Les différents mécanismes impliqués dans les systèmes de défense redox de l'érythrocyte normal sont bien connus. Ils sont ici passés en revue, en soulignant les principaux enzymes et voies métaboliques, tels que la superoxyde dismutase, la catalase, la glutathion peroxydase et réductase, le shunt hexose monophosphate (HMS) ainsi que la synthèse du glutathion et son renouvellement. Le stade intraérythro cytaire du Plasmodium induit, dans la cellule hôte, un stress oxydant, une production de $\mathrm{O}_{2}^{-}$et $\mathrm{H}_{2} \mathrm{O}_{2}$, une augmentation de la peroxydation des lipides et l'activation du HMS. Ce stress est induit au cours de la digestion de l'hémoglobine par le parasite. Ainsi, le parasite aussi bien que la cellule hôte doivent faire face à ce stress. Les systèmes antioxydants de défense du parasite et de la cellule infectée sont répertoriés ici et les problèmes non résolus soulignés. Le métabolisme du glutathion chez le parasite et les éventuelles interactions entre les systèmes de défense antioxydants de la cellule infectée et du parasite sont mal connus. Les postulats selon lesquels 1. I'HMS de la cellule hôte conjointement avec la voie de récupération des purines peut fournir des nucléotides puriques au parasite et 2. que la glutathion transférase peut participer à la résistance des parasites aux drogues antimalariques sont discutés.

which are still open for future research. The metabolic pathways and reactions discussed in this essay, are portrayed in Figure 1.

\section{THE ANTIOXIDANT DEFENCE SYSTEM OF NORMAL ERYTHROCYTES}

$\mathrm{R}$ eactive oxidative species (ROS) are produced in red blood cells (RBC) performing their main function of oxygen transport (reviewed by Rice-Evans, 1991), and therefore RBC are exquisitely well equipped to counteract the damage that can be produced by these radicals (Stern, 1985). Superoxide anions $\left(\mathrm{O}_{2}^{-}\right)$produced during the spontaneous oxidation of hemoglobin to methemoglobin are dismutated to $\mathrm{H}_{2} \mathrm{O}_{2}$ by superoxide dismutase (SOD). $\mathrm{H}_{2} \mathrm{O}_{2}$ is then reduced either by catalase or by glutathione (GSH)- peroxidase which catalyzes the general reaction $\mathrm{ROOH}+2 \mathrm{GSH} \rightarrow \mathrm{ROH}+\mathrm{GSSG}+\mathrm{H}_{2} \mathrm{O}$. In this function GHS-peroxidase is much more effective than catalase in the reduction of low concentrations of 


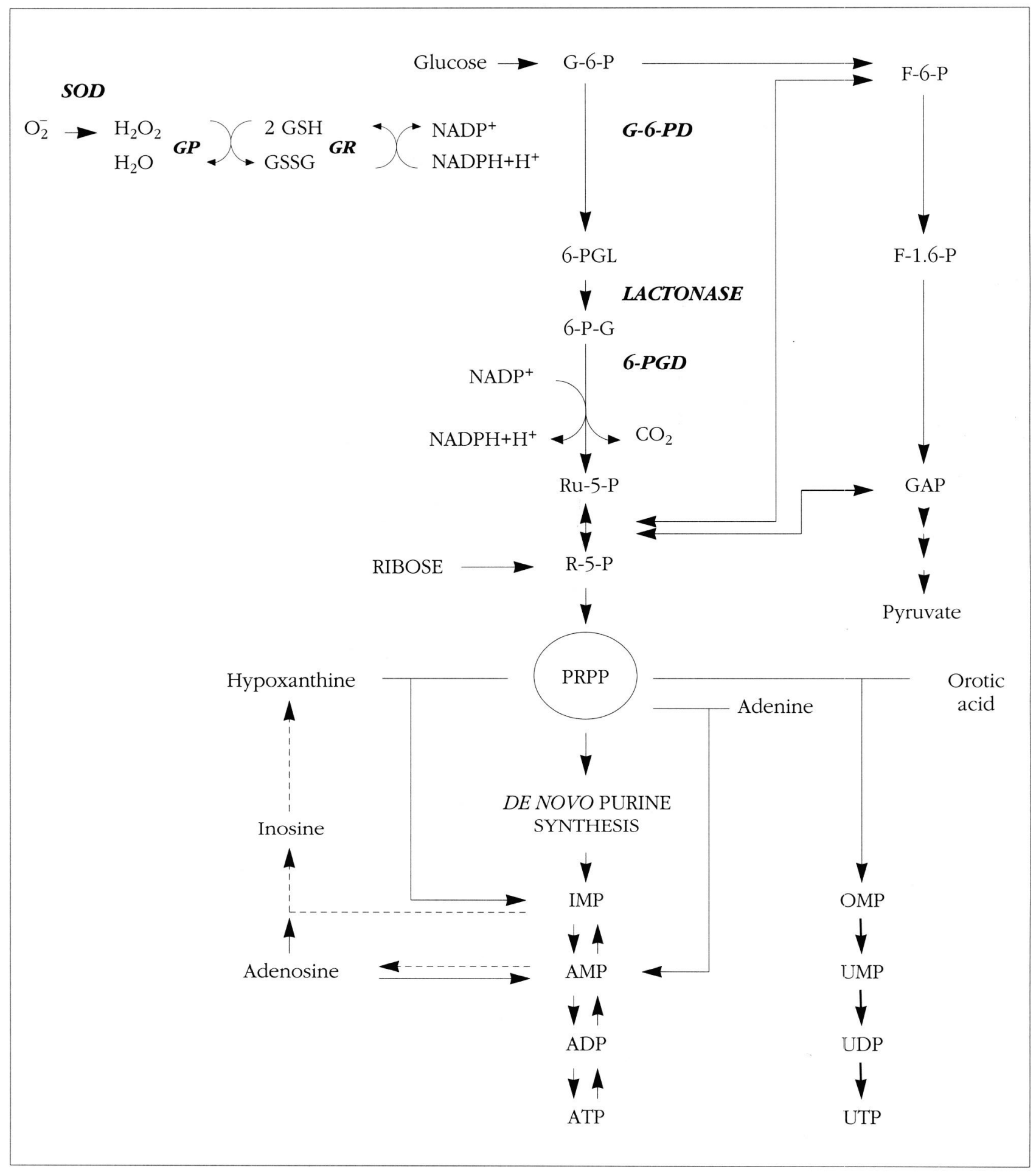

Fig. 1.

Schematic representation of the hexose monophosphate shunt (center), its connections to glycolysis (right-hand side) via the transaldolase and transketolase reactions (arrows), to the redox defence enzymes (left-hand), to purine and pyrimidine nucleotide synthesis (lower part), and to purine salvage (broken arrows). G-1-P : glucose-1-phosphate ; G-6-P : glucose-6-phosphate ; F-6-P : fructose-6-phosphate ; F-1,6-P : fructose-1,6-diphosphate ; GAP : glyceraldehyde-3-phosphate ; 6PGL : 6-phosphogluconolactone ; 6-P-G : 6-phosphogluconate ; Ru-5-P : ribulose-5-phosphate ; R-5-P : ribose-5-phosphate ; PRPP : 5-phosphoribosyl-1-pyrophosphate ; NADP ${ }^{+}$: nicotinamide adenine monophosphate ; ADP : adenosine diphosphate ; ATP : adenosine triphosphate ; OMP : orotidine monophosphate ; UMP : uridine monophosphate ; UDP : uridine diphosphate ; UTP : uridine triphosphate ; GSH : reduced glutathione ; GSSG : oxidized glutathione ; G-6-PD : glucose-6-phosphate dehydrogenase ; 6-PGD : 6-phosphogluconate dehydrogenase ; GP : glutathione peroxidase ; GR : glutathione reductase ; SOD : superoxide dismutase. 
$\mathrm{H}_{2} \mathrm{O}_{2}$. GSH-peroxidase is very sensitive to SH-reagents and to oxidative attack, notably the superoxide anion. GSH is a hydrogen donor for GSH-peroxidase, and the GSH/GSSG ratio reflects the steady-state concentration of ROS. GSSG is reduced to GSH by GSH-reductase which catalyzes the reaction

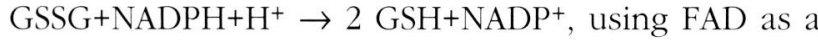
cofactor. GSHR is tightly regulated : it is inhibited by NADPH and low GSSG, and is activated by high GSSG concentrations (Lopez-Barea \& Lee, 1979). $\mathrm{NADP}^{+}$is reduced back to NADPH by the hexose monophosphate shunt.

\section{GLUTATHIONE}

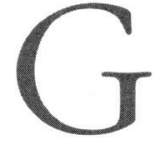

$\mathrm{SH}(\boldsymbol{\gamma}$-Glu-CysH-Gly) plays a pivotal role in the redox metabolism, and is thus widely distributed in animal tissues, plants and microorganisms. It is typically present in high (0.1-10 $\mathrm{mM}$ ) levels and is thus both the most prevalent cellular thiol and the most abundant low molecular weight peptide. GSH protects cells from reactive oxidative compounds (Sies, 1986) and is important in the regulation of pyridine nucleotides which provides cells with reducing power. It functions in catalysis, metabolism and transport, and participates in the synthesis of proteins and nucleic acids, in the detoxification of peroxides and free radicals; GSH forms conjugates with a variety of compounds of endogenous and exogenous origin, and is a cofactor of various enzymes.

Beutler and Dale (1989) have recently reviewed the metabolism and function of GSH in red blood cells (RBC). Normal RBC contain $\mathrm{mM}$ levels of GSH, most of it is in the reduced form. GSH is synthesized in erythrocytes (as in other cells) in two consecutive reactions, the first catalyzed by $\gamma$-Glu-Cys synthetase forming $\gamma$-Glu-CysH from Glu and Cys (Glu+Cys+ATP $\rightarrow \gamma$-Glu-CysH+ADP+Pi), and the second by GSH synthetase, adding a glycine to the dipeptide $($ Glu+Cys+ATP $\rightarrow \boldsymbol{\gamma}$-Glu-CysH+ADP+Pi). $\boldsymbol{\gamma}$-Glu-Cys synthetase is feedback inhibited by GSH. The half-life of GSH in erythrocytes is 4 days under normal conditions, mostly due to the ATP-dependent efflux of oxidized GSH (GSSG). Oxidative challenge of RBC usually results in increased efflux of GSSG and of GSH turnover. Two GSSG transport systems have been identified, one of high affinity $(\mathrm{Km}=0.1 \mathrm{mM})$ and low capacity, and the other displaying low affinity $(\mathrm{Km}=7 \mathrm{mM})$ and high capacity, which also mediates the efflux of thioether conjugates of xenobiotics (including some drugs). The role of the first system is to protect the cell from the toxic effects of GSSG, such as the inhibition of the glycolysis pathway enzymes hexokinase, phosphofructokinase and pyru- vate kinase, and it is markedly activated under conditions of oxidative stress when large amounts of GSH are used by GSH-peroxidase. This can be easily replenished by de novo synthesis whose maximal capacity would provide for a turnover half-time of 17 minutes (340-fold increase over normal). It has been suggested that only the high affinity system can transport GSSG, while both systems can mediate the efflux of GSH adducts (Labelle et al., 1986). GSH can also react directly with oxidative radicals, yielding the thiyl radical GS $S^{\bullet}$ which can react with thiolate anion and then with $\mathrm{O}_{2}^{-}$to form $\mathrm{O}_{2}^{-}$that is subsequently handled by SOD and catalase (Munday \& Winterbourn, 1989). Thus, suppression of chain oxidation of GSH is an important function of SOD, and the combination of SOD and GSH constitutes an integral component of cellular antioxidant defence.

\section{THE HEXOSE MONOPHOSPHATE SHUNT}

$\mathrm{N}$ ADPH is the sole substrate for GSH-reductase and it is also essential for protecting catalase from $\mathrm{H}_{2} \mathrm{O}_{2}$ thus assuring its continuous function (Kirkman et al., 1987). Since NADPH is also required for various types of reductive biosyntheses, it must be constantly regenerated (Cohen \& Hochstein, 1963). The major source of cytoplasmic NADPH in most cells is the hexose monophosphate shunt (HMS ; also called pentose phosphate pathway) and specifically the two dehydrogenases of that pathway : glucose-6-phosphate dehydrogenase (G6PD) and 6-phosphogluconate dehydrogenase. G6PD catalyzes the initial, committed, and rate limiting step of the pathway. G6PD is thought to be controlled through inhibition by NADPH. It is doubly affected by the reduction of $\mathrm{NADP}^{+}$: as the NADP becomes $\mathrm{NADPH}$, less of the dinucleotide exists as the substrate, and more exist as an inhibitor that is competitive with $\mathrm{NADP}^{+}$. $\mathrm{NADP}^{+}$can also be reduced by glutamate dehydrogenase and isocitrate dehydrogenase. Whereas the first enzyme is absent from RBC, it is not clear what could be the mechanism that could produce isocitric acid in RBC from which mitochondria and the glyoxylate cycle are absent.

\section{INTERRELATIONSHIPS BETWEEN GLYCOLYSIS AND THE HEXOSE MONOPHOSPHATE SHUNT}

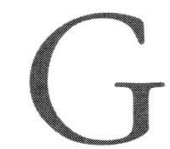

lycolysis produces ATP necessary for FAD and GSH synthesis, and NADH which provides reducing equivalents for met-hemoglobin reductase. Lactate, the final product of 
glycolysis, is also a source for reducing equivalents $(\mathrm{NADH})$ through lactate dehydrogenase. The ability of the cell to up-regulate glycolysis, HMS and GSSG detoxification provides efficient protection from oxidative damage under normal conditions and mild oxidative stress. Normally, 5-10 \% of the total glucose consumption in RBC passes through the HMS, and the flux is limited by the G6PD reaction which operates at less than $1 \%$ of its capacity at physiological levels of NADPH. Thus, glycolysis and HMS are controlled by the energetic and oxidative loads, respectively (Schuster et al., 1988). Under conditions of oxidative stress, i.e., high levels of GSSG, more than $80 \%$ of the 2 -fold increased glucose consumption passes through the HMS. In this case the velocity of GSSG reduction is rate-limited by the activity of hexokinase rather than by G6PD (Thorburn \& Kuchel, 1985), indicating that both glycolysis and HMS are tightly coupled (Schuster et al., 1988). This would mean that the tolerable oxidative load is severely restricted by an increasing energetic load, and vice versa.

\section{HEXOSE MONOPHOSPHATE SHUNT AND PURINE SALVAGE}

I $\mathrm{n}$ nucleated cells, the HMS is also responsible for the production of ribose-5-phosphate (R-5-P) for nucleic acid synthesis. R-5-P can be formed either from glucose-6-P in the oxidative direction of HMS, or from fructose-6-P and glyceraldehyde-3-P which are produced by glycolysis, in the transaldolase/transketolase non-oxidative pathway. R-5-P can then be converted to phosphoribosyl-PP (PRPP), and in presence of hypoxanthine, inosine monophosphate (IMP) is synthesized. Oxidative stress accelerates HMS and the levels of PRPP and IMP were found to be elevated in RBC (Yeh et al., 1984).

\section{THE REDOX STATUS OF MALARIA-INFECTED ERYTHROCYTES}

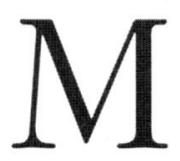

alaria-infected RBC (IRBC) are under endogenous oxidative stress. This presumption is supported by the demonstrable production of $\mathrm{H}_{2} \mathrm{O}_{2}$ by $P$. berghei-IRBC (Etkin \& Eaton, 1975) and $\mathrm{O}_{2}^{-}$by P. falciparum-IRBC (Hunt \& Stocker, 1990), and by increased levels of lipid peroxidation in $P$. berghei and $P$. chabaudi infected mouse RBC (Nakornchai \& Antanavara, 1992). We have recently demonstrated that its biochemical origin is the spontaneous oxidation and degradation of ingested hemoglobin in the acid environment of the parasite's food vacuole (Gabay \& Ginsburg, 1993 ; Atamna \& Ginsburg, 1993). To counteract this stress the parasite must possess its own defence or rely on that of the host cell. Although some parasite enzymes involved in redox metabolism have been identified, no compartmental analysis of the pertinent substrates and products has been performed to understand the redox metabolism of the parasite, or that of the infected host cell.

\section{ANTIOXIDANT ENZYMES}

S ince the parasite digests its host cell cytosol, the concentration of host enzymes/cell must decline with parasite maturation. As mature mammalian RBC are incapable of de novo protein synthesis, changes in the level of an enzyme in the infected cell reflect the ability of the parasite to synthesize it. The parasite is apparently endowed with the enzymatic machinery to detoxify ROS, although species-specific differences exist. SOD activity decreases upon $P$. falciparum infection and there are convincing evidences that host SOD is "adopted" by the parasite (Fairfield et al., 1983 ; Stocker et al., 1985 ; Fairfield et al., 1988). However, this "adopted" SOD may be superfluous since it resides in the acidic food vacuole of the parasite where spontaneous dismutation (accelerated by $\mathrm{H}^{+}$) may be sufficient to transform $\mathrm{O}_{2}^{-}$to $\mathrm{H}_{2} \mathrm{O}_{2}$. In comparison, SOD levels in $P$. berghei IRBC were found to be increased (Seth et al., 1985) and it has been recently demonstrated that murine parasites contain a Fe-SOD, in contradistinction with that of the host cell which is a $\mathrm{Cu}, \mathrm{Zn}-\mathrm{SOD}$ (Becuwe et al., 1993). The levels of catalase increase in P. falciparum (Fairfield et al., 1988) but decrease in P. berghei (Areekul \& Boonme, 1992).

Both $P$. berghei and $P$. falciparum contain elevated levels of GSH-peroxidase (Seth et al., 1985 ; Fairfield et al., 1988), but its contribution to $\mathrm{H}_{2} \mathrm{O}_{2}$ (vs that of catalase) is unknowm. Even if all the enzymes involved in the detoxification of ROS may work in infected cells, it is possible that they could not handle the vast production of ROS, given the fast transport of $\mathrm{O}_{2}^{-}$and the diffusion of $\mathrm{H}_{2} \mathrm{O}_{2}$ in conjunction with cellular dimensions. Indeed, we have shown that $\mathrm{H}_{2} \mathrm{O}_{2}$ produced by the parasite is partially handled by the host's catalase (Atamna \& Ginsburg, 1993), thus implicating the host cell in the antioxidant defence. Nevertheless, it is apparent that both host and parasite defence mechanisms may be insufficient to deal with all ROS produced by the parasite, since IRBC are extensively phagocytosed by a mechanism akin to that observed in oxidatively stressed RBC (Turrini et al., 1992). 


\section{GLUTATHIONE STATUS IN MALARIA-INFECTED CELLS}

S ince parasites also have GSH-reductase activity (Zhang et al., 1988), conditions exist for the participation of the GSH cycle in the antioxidant defence. The levels of GSH were determined in intact malaria-infected RBC. In murine malarias the level of GSH was found to increase upon infection (PickardMoreau et al., 1975 ; Eckman \& Eaton, 1979 ; Seth et al., 1985), but not in P. falciparum (Roth et al., 1982 ; Zhang et al., 1988). Most interestingly, Roth et al. (1986a) failed to detect any GSH in parasites growing in G6PD-deficient RBC infected with $P$. falciparum, implying that the parasite may be totally dependent on host cell GSH synthesis and the GSH must be able to translocate from the host to the parasite, but this has not been tested directly. In all the studies mentioned above the levels of GSSG have not been tested in spite of its role as a regulator of many enzymatic functions and as a reporter of oxidative stress. Very intriguingly, Eckman \& Eaton (1979) demonstrated that isolated P. berghei contain GSH, but that its maintenance in the reduced state depends on NADPH provided by the host cell, implicating host cell HMS in the reduction of parasite GSSG. Such mechanism requires that the parasite membrane is permeable to NADPH, unless other mechanism(s) exists to translocate the reducing power. Such mechanism exists in mitochondria, involving the malateaspartate shuttle (for NADH) and the tricarboxylic carrier and isocitrate dehydrogenase (for NADPH), but their presence in the infected cell has not been tested. In this context it should be mentioned that RBC contain high levels of aspartate transaminase. This is not only an essential constituent of the malate-aspartate shuttle, but can also generate Glu (and oxaloacetate) from Asp and $\alpha$-ketoglutarate. It may be very interesting to verify whether such mechanisms are also present in the parasite membrane which has already been demonstrated by us to contain the typical mitochondrial ATP/ADP exchanger (Kanaani \& Ginsburg, 1989). Finally, it should be emphasized that parasites propagating inside G6PD-deficient RBC are more prone to oxidative stress, be it high oxygen tension (Friedman, 1979), exposure to diamide (Miller et al., 1984 ; Golenser et al., 1988) or menadione, or the protective effect of dithiotreitol (Friedman, 1979). These results strongly imply an interconnection between parasite and host cell redox metabolic pathways.

\section{PUZZLES CONCERNING GSH SYNTHESIS AND TURNOVER IN IRBC}

$\mathrm{E}$ ssentially nothing is known about GSH synthesis in the parasite, nor have the relevant enzymes been identified. As mentioned ear- lier, normal RBC are capable of accelerating their GSH synthesis 340-fold (Beutler \& Dale, 1989), and thus could, in principle, meet the oxidative challenge imposed by the parasite and provide GSH to the parasite. We have recently observed a considerable enhancement of GSSG efflux from intact IRBC or from isolated parasites (Atamna \& Ginsburg, unpublished observations). This implies an accelerated turnover of GSH in IRBC and indirectly, the ability of the parasite to synthesize GSH. GSH synthesis in RBC is rate-limited by the supply of Glu. In IRBC Glu could be provided either endogenously by the digestion of host cell cytosol, or exogenously by the increased permeability of IRBC to Glu (Ginsburg et al., 1985), although others failed to observe it (Elford et al., 1985), or to $\mathrm{GluNH}_{2}$ which can be converted to Glu by glutaminase. Elford and Pinches (1992) suggested that Glu is produced from $\mathrm{GluNH}_{2}$ by Glu-synthase (GluHN $_{2}$ amide 2-oxoglutarate amidotransferase). However, the sole endogenous source for oxoglutarate is Glu itself (through Glu dehydrogenase) and the pathway suggested above could not result in net Glu production. If the parasite is able to produce GSH by itself, could host cell and parasite GSH synthesis be interconnected through the translocation of $\gamma$-Glu-Cys (the substrate of GSH synthetase) produced in either compartment? Such interrelationship could in principle increase the levels of GSH in one compartment when the levels of GSSG are elevated in the other, because the synthesis of $\gamma$-Glu-Cys itself will not be under the control of GSH.

\section{HEXOSE MONOPHOSPHATE SHUNT}

T he maintenance of GSH requires NADPH to fuel GSHR. In most types of cells the reduction of $\mathrm{NADP}^{+}$is mediated by HMS. The activity of HMS has been measured in intact infected cells, and was found to be increased (compared to uninfected RBC) in P. berghei (Neame \& Homewood, 1975), P. knowlesi (Shakespeare et al., 1979) and P. falciparum (Roth et al., 1982). G6PD, which catalyzes the initial, committed, and rate limiting step of HMS, has been identified in these parasite species, isolated and characterized (Theakston \& Fletcher, 1973 ; Buckwitz et al., 1990 ; Kurdi-Haidar \& Luzzatto, 1990). Its presence could account for the increased HMS activity, and we were recently able to measure it in isolated parasites, and by comparing its rate to that observed in intact IRBC, to conclude that the host's HMS activity is increased some 25-fold, possibly due to its activation by ROS produced by the parasite (Atamni \& Ginsburg, in preparation). 


\section{ADDITIONAL POSSIBLE MECHANISMS FOR THE REDUCTION OF NADP+}

$\mathrm{T}$ wo additional mechanisms for the reduction of $\mathrm{NADP}^{+}$have been demonstrated in various plasmodium species, namely glutamate dehydrogenase (GDH ; Sherman et al., 1971 ; Walter et al., 1974 ; Roth et al, 1982 ; Vander Jagt et al, 1989) and isocitrate dehydrogenase (IDH. Vander Jagt et al, 1989 ; Sahni et al., 1992). However, GDH was shown to be mostly active in the direction of glutamate synthesis from $\alpha$-ketoglutarate (Vander Jagt et al, 1989), and no isocitrate could be detected in IRBC, although the pathway for its production has been suggested (Scheibel, 1988). Hence, it remains to be shown what is the actual contribution of these mechanisms for the generation of NADPH in the parasite.

\section{THE PARASITE IS UNDER ENERGETIC LOAD}

I $t$ must be underscored that the parasite is not only under oxidative load but may be also under energetic load. Its glycolytic activity is up to 100fold larger than that of the host cell (Pfaller et al, 1982), and part of the ATP produced by glycolysis is supplied to the host cell (Kanaani \& Ginsburg, 1989), whose own glycolysis may be suboptimal because its cytosol is more acid than normal (Ginsburg, 1990). This may mean that both HMS and glycolysis in the parasite are rate-limited by its hexokinase. The latter's activity is some 8-fold higher in IRBC (Roth, 1987).

Studies of reduced : oxidized pyridine nucleotide ratio in infected cells have produced conflicting results (Sander \& Kruckeberg, 1981 ; Nagarajan, 1964 ; Sherman, 1966), but there is no obvious tendency towards increased oxidation, suggesting that the parasite has ample capacity for the reduction of both $\mathrm{NAD}^{+}$and $\mathrm{NADP}^{+}$. Since plasma concentrations of lactate and pyruvate are the major determinants of the glycolytic response to oxidative stress (Sullivan \& Stern, 1983, 1984), pyruvate accumulation is a parameter of oxidative stress. Both in falciparum and in berghei malarias, lactic acidosis was observed, in parallel with hypoglycemia and hyperpyruvicaemia, yet the lactate/pyruvate ratio was always elevated (White et al., 1985 ; Holloway et al., 1991). Interestingly, it has been recently reported that $P$. falciparum-infected $\mathrm{RBC}$ are in fact more resistant to oxidative challenge compared to uninfected RBC, and that they confer this resistance also to co-cultured non-infected RBC (Simoes et al., 1992).

\section{HEXOSE MONOPHOSPHATE SHUNT AND NUCLEIC ACID SYNTHESIS}

I f the parasite possesses its own HMS, it could use it both for the generation of NADPH and for the production of R-5-P required for the synthesis of nucleic acids through the production of PRPP. Roth et al. (1986b) have provided evidence the R-5-P incorporated into parasite DNA originates exclusively from the non-oxidative activity of HMS (production of R-5-P from fructose-6-phosphate and glyceraldehyde3-phosphate originating from glycolysis through the concerted action of transketolase and transaldolase). In our hands the parasite is capable of producing appreciable amounts of ${ }^{14} \mathrm{CO}_{2}$ from $\mathrm{C}_{1}$ but not from $\mathrm{C}_{6}$ labelled glucose, indicating that it has substantial HMS activity. Using $13 \mathrm{C}$-NMR techniques, it has been recently shown in $\mathrm{RBC}$ that there is an observable flux of fructose-6-phosphate through the reactions catalyzed by transketolase and transaldolase, even in the presence of a net flux through HMS (Schrader et al, 1993), thus reconciling the apparent contradiction between Roth's date and ours. The only HMS enzymes demonstrated so far in parasites are G6PD and 6-phosphogluconate dehydrogenase (Scheibel, 1988).

\section{POSSIBLE CONSEQUENCES OF INCREASED HOST HMS ACTIVITY FOR PARASITE NUCLEIC ACID SYNTHESIS}

S ince oxidatively stressed RBC contain higher levels of PRPP (Yeh et al., 1985), it is tempting to suggest that the oxidative stress impinged on the host cell by the parasite may have a physiological benefit for the parasite by increasing the levels of PRPP. Roth et al. (1986b) have detected increased levels of PRPP in normal RBC infected with $P$. falciparum and lower levels in G6PD-deficient IRBC. Since a parallel difference was seen in the levels of GSH, they concluded that GSH controls PRPP synthetase. Although the distribution of either GSH or PRPP have not been tested, these results indicate that the parasite is capable of synthesizing PRPP, but since the parasite grows better in normal RBC, they may also imply that the host cell supplies PRPP to the parasite. It is very unlikely, however, that such highly charged molecule could possibly translocate across the parasitophorous and the parasite cell membranes. However, in the presence of hypoxanthine, high levels of PRPP usually effect an accelerated synthesis of inosine monophosphate (IMP). We have recently observed that the synthesis of ATP in isolated parasites is substantially greater in presence of IMP than 
in that of hypoxanthine in the incubation medium (Ginsburg et al., to be published). These deliberations may suggest that the oxidative stress impinged by the parasite on the host cell may benefit the nucleotide synthesis of the parasite.

\section{CONCLUDING REMARKS}

A Ithough it seems that the antioxidant defence of the malaria parasite is in principle comparable to that used by other eukaryotes, much remains to be learned about the redox metabolism. The metabolism of glutathione is virtually unknown in terms of enzyme activities, the supply of substrates and the mechanism of GSSG efflux. The physiological functions of glutamate and isocitrate dehydrogenases in the reduction of $\mathrm{NADP}+$, remain to be established. One of the outstanding perception that stem from this brief essay, is that the antioxidant defence systems of the host cell and the parasite may be interconnected. Whereas this contention seems intelligible if parasitism is contemplated as a station in the evolution of symbiosis, the details of this insinuated relationship(s) call for detailed investigations. Filling the existing gaps in our understanding of the redox metabolism of the malaria-infected RBC, may also distinguish new targets which could be used for the rational development of new antimalarial drugs.

Finally, the enzyme GSH-transferase readily conjugates compounds with an electrophillic character with GSH. This is a major mechanism for the detoxification of xenobiotics (Baillie \& Slatter, 1991), including drugs. Drug resistance in cancer cells has been correlated in some instances with overexpression of the enzyme, and with elevated levels of GSH (Mattern \& Volm, 1993). Such may also be the case in malaria, but this avenue of drug resistance has not been contemplated yet. It has been a mainstay of anticancer therapy that inhibitors of $\gamma$-Glu-Cys synthetase can revert drug resistance. GSH depletion is effective therapeutically when the normal and the tumor cells have markedly different requirements for GSH. Most normal cells have a large excess of GSH, but certain tumors and parasites have levels close to those required for survival. If this will be found also to be the case for the malarial parasite, the co-administration of drugs with inhibitor(s) of GSH synthesis may constitute a new tactic for the reversal of drug resistance.

\section{REFERENCES}

AREekul S. and Boonme Y. : Catalase activity in red cell and liver of mice infected with Plasmodium berghei, in :Lipid-Soluble Antioxidants. Biochemistry and Clinical
Applications. Ong, A.S.H. and Packer L. (eds), Birkhauser Verlag, Basel, 1992, 416-423.

Atamna H. and Ginsburg H. : Origin of reactive oxygen species in erythrocytes infected with Plasmodium falciparum. Molecular and Biochemical Parasitology, 1993, 61, 231-242.

Baillie T.A. and Slatter J.G. : Glutathione : A vehicle for the transport of chemically reactive metabolites in vivo. Accounts of Chemical Research, 1991, 24, 264-270.

Becuwe P., Slomianny C., Camus D. and Dive D. : Presence of an endogenous superoxide dismutase activity in 3 rodent malaria species. Parasitology Research, 1993, 79, 349-352.

Beutler E. and Dale G.L. : Erythrocyte glutathione : Function and metabolism, in: Coenzymes and Cofactors. Glutathione. Chemical, Biochemical and Medical aspects, Part B (Dolphin D. Poulson R. and Avramovic O., eds), Wiley, New York, 1989, 291-317.

Buckwitz D., Schonian G., Holzhutter H.G. and Jacobasch G. : Kinetic model of glucose-6-phosphate dehydrogenase from red blood cells. Parameter estimation from progress curves and simulation of regulatory properties. Biomedica Biochimica Acta, 1986, 45, 429-439.

Cohen G. and Hochstein P. : Glutathione peroxidase. The primary agent for the elimination of hydrogen peroxide in erythrocytes. Biochemistry, 1963, 2, 1420-1428.

ECKMAN J.R. and EATON J.W. : Dependence of plasmodial glutathione metabolism on the host cell. Nature, 1979, 278, 754-756.

Elford B.C., Haynes J.D., Chylay J.D. and Wilson R.J.M. : Selective stage-specific changes in the permeability to small hydrophyllic solutes of human erythrocytes infected with Plasmodium faciparum. Molecular and Biochemical Parasitology, 1985, 16, 43-60.

ElFord B.C. and Pinches R.A. : Inducible transport system in the regulation of parasite growth in malaria-infected red blood cells. Biochemical Society Transactions, 1992, 20, 790-796.

ETKin N.L. and EATON J.W. : Malaria-induced erythrocyte oxidant sensitivity, in: Erythrocyte Structure and Function. Brewer G.J. (ed.), A.R. Liss. New York, 1975, 219-234.

FAirfield A.S., Meshnick S.R. and EATON J.W. : Malaria parasites adopt host cell superoxide dismutase. Science, 1983, 221, 764-766

Fairfield A.S., Eaton J.W. and Meshnick S.R. : Superoxide dismutase and catalase in the murine malaria, Plasmodium berghei : Content and subcellular distribution. Archives of Biochemistry and Biophysics, 1986, 250, 526-529.

Fairfield A.S., Abosch A., Ranz A., Eaton J.W. and Meshnick S.R. : Oxidant defence enzymes of Plasmodium falciparum. Molecular and Biochemical Parasitology, 1988, 30, 77-82.

FriEDMAN M.J. : Oxidant damage mediates variant red cell resistance to malaria. Nature, 1979, 280, 245-247.

Gabay T. and Ginsburg H. : Hemoglobin denaturation and iron release in acidified red blood cell lysate - a possible source of iron for intraerythrocytic malaria parasites. Experimental Parasitology, 1993, 77, 261-272. 
Ginsburg H., Kutner S., Krugliak M. and Cabantchik Z.I. : Characterization of permeation pathways appearing in the host membrane of Plasmodium falciparum infected red blood cells. Molecular and Biochemical Parasitology, $1985,14,313-322$.

GINSBURG H. : Some reflections concerning host erythrocytemalarial parasite interrelationships. Blood Cells, 1990, 16, 225-235.

GOLENSER J. and Chevion M. : Oxidant stress and malaria : Host-parasite interrelationships in normal and abnormal erythrocytes. Seminars in Hematology, 1989, 26, 313-325.

Golenser J., Miller J., Spira D.T., Kowoser N.S., Vande WaA J.A. and Jensen J.B. : Inhibition of the intraerythrocytic development of Plasmodium falciparum in glucose-6phosphate dehydrogenase deficient erythrocytes is enhanced by oxidants and crisis form factor. Tropical Medicine and Parasitology, 1988, 39, 273-276.

Holloway P.A.H., Krishna S. and White N.J. : Plasmodium berghei : Lactic acidosis and hypoglycemia in a rodent model of severe malaria. Experimental Parasitology, 1991, 72, 123-133.

Hunt N.H. and Stocker R. : Oxidative stress and the redox status of malaria-infected erythrocytes. Blood Cells, 1990, 16, 499-526.

KanaAni J. and Ginsburg H. : Metabolic interconnection between the human malarial parasite Plasmodium falciparum and its host erythrocyte : Regulation of ATP levels by means of an adenylate translocator and adenylate kinase. Journal of Biological Chemistry, 1989, 264, 3194-3199.

Kirkman H.N., Galiana S. and Gaetani G.F. : The function of catalase-bound NADPH. Journal of Biological Chemistry, 1987, 262, 660-666.

Kurdi-Haidar B. and Luzzatto L. : Expression and characterization of glucose-6-phosphate dehydrogenase of Plasmodium falciparum. Molecular and Biochemical Parasitology, 1990, 41, 83-92.

Labelle E.F., Singh S.V., SRivastava S.K. and Awasthi Y.C. Dinitrophenol glutathione efflux from human erythrocytes is primary active ATP-dependent transport Biochemical Journal, 1986, 238, 443-449.

LOPEZ-BAREA J. and LEE C. : Mouse-liver glutathione reductase. European Journal of Biochemistry, 1979, 98, 487499 .

Mattern J. and Volm M. : Multiple Pathway Drug Resistance (Review). International Journal of Oncology, 1993, 2, 557-561.

Miller J., Golenser J., Spira D.T. and Kosower N.S. : Plasmodium falciparum: Thiol status and growth in normal and glucose-6-phosphate dehydrogenase deficient human erythrocytes. Experimental Parasitology, 1984, 57, 239-247.

Munday R. and Winterbourn C.C. : Reduced glutathione in combination with superoxide dismutase as an important biological antioxidant defence mechanism. Biochemical Pharmacology, 1989, 38, 4349-4352.

Nagarajan K. : Pyruvate and lactate levels in relationship to the nicotinamide-adenine dinucleotide levels in malarial parasite (Plasmodium berghei). Biochimica et Biophysica Acta, 1964, 93, 176-179.
NAKORnChai S. and Anantavara S. : Oxygen free radicals in malaria, in : Lipid-Soluble Antioxidants, Biochemistry and Clinical Applications. Ong, A.S.H. and Packer L. (eds), Birkhauser Verlag, Basel, 1993, 355-362.

NeAmE K.D. and Homewood C.A. : Alterations in the permeability of mouse erythrocytes infected with the malaria parasite Plasmodium berghei. International Journal of Parasitology, 1975, 5, 537-540.

Pfaller M.A., Krogstad D.J. and Parquette A.R. : Plasmodium falciparum : Stage-specific lactate production in synchronized cultures. Experimental Parasitology, 1982, 54, 391-396

Pickard-Moreau A., Hempelmann E., Krammer G., Jackisch R. and Jung A. : Glutathionstatus in Plasmodium vinckei parasitieren Erythrozyten in Abhangigkeit vom intraerytrozyaren Entwicklungsstadium des Parasiten. Tropenmedizin und Parasitologie, 1975, 26, 405-416.

RiCE-Evans C. : Iron-mediated oxidative stress in erythrocytes, in : Blood Cell Biochemistry, vol. 1, Erythroid Cells, Harris J.R. (ed), Plenum Press, New York, 1990, 429-453.

Rотн E.F. : Malarial parasite hexokinase and hexokinasedependent glutathione reduction in the Plasmodium falciparum-infected human erythrocyte. Journal of Biological Chemistry, 1987, 262, 15678-15682.

Roth E.F., Raventos-Suarez C., Perkins M. and Nagel R.L. : Glutathione stability and oxidative stress in $P$. falciparum infection in vitro : responses of normal and G6PD deficient cells. Biochemical and Biophysical Research Communications, 1982, 109, 355-362.

Roth E.F., Schulman S., Vandenberg J. and Olson J. : Pathways for the reduction of oxidized glutathione in the Plasmodium falciparum-infected erythrocytes : Can parasite enzymes replace host red cell glucose-6-phosphate. Blood, 1986a, 67, 827-830.

Roth E.F., Ruprecht R.M., Schulman S., Vandenberg J. and OLsON J.A. : Ribose metabolism and nucleic acid synthesis in normal and glucose-6-phosphate dehydrogenasedeficient human erythrocytes infected with Plasmodium falciparum. Journal of Clinical Investigations, 1986b, 77, 1129-1135.

Sahni S.K., SaXena N., Puri S.K., Dutta G.P. and Pandey V.C. : NADP-specific isocitrate dehydrogenase from the simian malaria parasite Plasmodium knowlesi - partial purification and characterization. Journal of Protozoology, 1992, 39, 338-342

SAnder B.J. and Kruckeberg W.C. : Plasmodium berghei : Glycolytic intermediate concentrations of the infected mouse erythrocyte. Experimental Parasitology, 1981, 52, $1-8$.

SCHeIBEL L.W. : Plasmodial metabolism and related organellar function during various stages of the life cycle : Carbohydrates. in : Malaria : Principles and Practices of Malariology (Wernsdorfer W.H. and McGregor I., eds), Churchill Livingstone, Edinburgh, 1988, 199-212.

Schrader M.C., Simplaceanu V. and Ho C. : Measurement of fluxes through the pentose phosphate pathway in erythrocytes from individuals with sickle cell anemia by carbon-13 nuclear magnetic resonance spectroscopy. Biochimica et Biophysica Acta, 1993, 1182, 179-188. 
Schuster R., Holzhutter H.G. and Jacobash G. : Interrelations between glycolysis and the hexose monophosphate shunt in erythrocytes as studied on the basis of a mathematical model. BioSystems, 1988, 22, 19-36.

Seth R.K., Sahni A.S. and Jaswal T.S. : Plasmodium berghei : oxidant defense system. Experimental Parasitology, 1985, 60, 414-416.

Shakespeare P.G., Trigg P.I., Kyd S.I. and Tappenden L. : Glucose metabolism in the simian malaria parasite Plasmodium knowlesi : Activities of the glycolytic and pentose phosphate pathways during the intraerythrocytic cycle. Annals of Tropical Medicine and Parasitology, 1979, 73, 407-415.

Sherman I.W., Peterson I., Tanigoshi L. and Ting I.P. : The glutamate dehydrogenase of Plasmodium lophurae (avian malaria). Experimental Parasitology, 1979, 29, 433-439.

SHERMAN I.W. : Levels of oxidized and reduced pyridine nucleotides in avian malaria (Plasmodium lophurae). American Journal of Tropical Medicine and Hygiene, $1966,15,814-817$.

Sies H. : Biochemistry of oxidative stress, Angewandet Chemie, International Edition (English), 1986, 25, 10581071.

Simoes A.P.C.F., Vandenberg J.J.M., Roelofsen B. and Opdenkamp J.A.F. : Lipid peroxidation in Plasmodium falciparum-parasitized human erythrocytes. Archives of Biochemistry and Biophysics, 1992, 298, 651-657.

STERN A. : Red cell oxidative damage. in : Oxidative Stress, Sies H. (ed.), Academic Press, London, 1985.

Stocker R., Hunt N.H., Buffinton G.D., Weideman M.J., LEWISHugh P.H. and Clark I.A. : Oxidative stress and protective mechanisms in erythrocytes in relation to Plasmodium vinckei load, Proceedings of the National Academy of Sciences, USA, 1985, 82, 548-551.

Sullivan S.G. and STERN A. : Effects of physiologic concentrations of lactate, pyruvate and ascorbate on glucose metabolism in unstressed and oxidatively stressed human red blood cells. Biochemical Pharmacology, 1983, 32, 2891-2902.

Sullivan S.G. and STERn A. : Glucose metabolism of oxidatively stressed human red blood cells incubated in plasma or medium containing physiologic concentrations of lactate, pyruvate and ascorbate. Biochemical Pharmacology, 1984, 33, 1417-1421.

Theakston R.D.G. and Fletcher K.A. : An electron cytochemical study of glucose-6-phosphate dehydrogenase activity in malaria-infected erythrocytes. Life Sciences, 1973, 13. 405-410.

Thorburn D.R. and Kuchel P.W. : Regulation of human erythrocyte hexose-monophophate shunt under conditions of oxidative stress. European Journal of Biochemistry, 1985, 150, 371-386.

Turrini F., Ginsburg H., Bussolino F., Pescarmona G.P., SERRA M.V. and ARESE P. : Phagocytosis of Plasmodium falciparum-infected human red blood cells by human monocytes - involvement of immune and nonimmune determinants and dependence on parasite developmental stage. Blood, 1992, 80, 801-808.

Vander Jagt D.L., Hunsaker L.A., Kibrige M, and Campos N.M. : NADPH production by the malarial parasite Plasmodium falciparum. Blood, 1989, 74, 471-474.

Vennerstrom J.L. and Eaton J.W. : Oxidants, oxidant drugs, and malaria. Journal of Medicinal Chemistry, 1988, 31, 1269-1277.

Walter R.D., Nordmeyer J.P. and Konigk E. : NADP-specific glutamate dehydrogenase from Plasmodium chabaudi. Hoppe-Seyler's Zeitschrift für Physiologisches Chemie, 1974, 355, 495-500.

White N.J., Looareesuwan S., Chanthavanich P., Phillips R.E. and PongPaEw P. : Pathophysiological and prognostic significance of cerebrospinal fluid lactate in cerebral malaria. The Lancet, 1985, I, 776-778.

Winterbourn C.C. and Stern A. : Human red cells scavange extracellular hydrogen peroxide and inhibit formation of hypochlorous acid and hydroxyl radicals. Journal of Clinical Investigations, 1987, 80, 1486-1491.

Yeh G.C., Roth E.F.Jr, Phang J.M., Harris S.C., Nagel R.L. and Rinaldi A. : The effect of pyrroline-5-carboxylic acid on nucleotide metabolism in erythrocytes from normal and glucose-6-phosphate dehydrogenase-deficient subjects. Journal of Biological Chemistry, 1984, 259, 54545458.

Zhang Y., Konig I. and Schirmer R.H. : Glutathione reductase-deficient erythrocytes as host cells of malarial parasites. Biochemical Pharmacology, 1988, 37, 861-865. 